\title{
Symptom relief and the placebo effect in the trial of an anti-peptic drug
}

\author{
A J MACDONALD, N R PEDEN, R HAYTON, C N MALLINSON, \\ D ROBERTS, AND K G WORMSLEY
}

From the University Departments of Psychiatry and of Therapeutics, Ninewells Hospital and Medical
School, Dundee, Greenwich District Hospitals, London, and the Royal Army Medical College,
Millbank, London

SUMMARY In order to determine some of the factors involved in the response of duodenal ulcers to placebo treatment, the following factors were studied prospectively during a double-blind, placebocontrolled trial: demographic data; duration of illness and effect of treatment; expectation of success or failure of the new drug; presence of psychiatric problems; and suggestibility. Healing (measured by endoscopy) occurred in 37 patients, 17 of whom were receiving placebo; relief of symptoms occurred in 35 patients, 16 of whom were receiving placebo. There was no significant difference between drug and placebo. Healing was significantly associated with relief of symptoms but with no other variable. Relief of symptoms was more common in male patients and in those from higher social classes, as well as in patients who expected a complete cure and those without evidence of psychiatric problems. The natural history of the disease may be different in these patients. Unexpectedly, suggestibility was not associated with healing or relief of symptoms in the patients receiving placebo.

The 'placebo effect' (the increased healing of, for example, duodenal ulcers during treatment with placebo) is a well-recognised but little understood phenomenon which makes the interpretation of therapeutic trials extremely difficult. For any patient with any illness, response to treatment $=$ natural healing + placebo effect + effects of drug (or other treatment). For example, during recent randomised double-blind studies of cimetidine in healing duodenal ulcers, the proportion of patients whose ulcers healed or whose symptoms were relieved during treatment with placebo tablets ranged from less than $20 \%$ to over $80 \%{ }^{1}$ The determinants of the placebo effect have been difficult to identify, as neither personality type nor therapeutic situation are specific for such effects. As expectations about the results of treatment influence the response to therapy, ${ }^{2}$ it has been found necessary to undertake therapeutic trials on the basis of 'double-blind' ignorance of the type of treatment (whether active or placebo) on the part of both investigator and

Received for publication 30 October 1980 patient. Placebo response has also been correlated with the suggestibility of the subject undergoing study. ${ }^{3}$

The present prospective study was undertaken in order to examine some of the factors which might be responsible for the placebo effect during a randomised double blind trial of an anti-peptic drug compared with placebo in the healing of duodenal ulcers.

\section{Method}

Patients over 18 years old with endoscopically confirmed duodenal ulcers were admitted to the trial in two centres (Ninewells Hospital, Dundee, and Lewisham Hospital, London). Each patient was informed about the design of the trial, including the use of placebo, before consent was given. The patients were examined and interviewed throughout the trial by the same doctor in each of the two centres.

Endoscopy was repeated three weeks after starting the medication and after six weeks when the trial finished. The anti-peptic drug and placebo were 
identical tablets in identical packaging. Standard antacid tablets were provided for additional relief of pain, if required, and patients kept a diary of symptoms and of antacid consumption throughout the trial.

As soon as possible after admission to the trial, each patient completed a questionnaire including enquiry about demographic data, duration of illness, time lost from work through illness, previous treatment and its efficacy, and expectations of results from the new treatment. As the trial was doubleblind it was assumed that the doctors' expectations of the results of therapy would not differ significantly from one patient to another.

Each patient also completed the General Health Questionnaire (GHQ), ${ }^{4}$ a 60-item self-report questionnaire which can be used for psychiatric case identification. The questionnnaire is not designed to detect major psychiatric disorder, but it seemed unlikely that a significant number of new cases would arise in the test population during the therapeutic trial. A 'threshold' score was adopted according to Goldberg's criteria for a medical outpatient population, so that a GHQ score of 10 points or more identified a patient as having possible psychiatric disorder.

The Hull Body Sway test ${ }^{56}$ was carried out on each patient. The test assesses primary suggestibility by measuring the amount of sway that can be induced in a patient as a result of authoritative verbal instruction to the effect that the patient is swaying.

Instead of the original device employing a thread attached to the patient's clothing, a shoulder-borne frame was used, bearing a potentiometer linked to a pendulum recording back-and forward-movement on a pen recorder. (Full details of the Body Sway apparatus may be obtained from Mr A Bell, Senior Technician, Department of Psychiatry, Ninewells Hospital, Dundee, DD2 1UB, Scotland). Identical instruments were used in both trial centres. To ensure uniformity, the same instructions were used in both centres, tape-recorded in the voice of the tester for that area. Thirty seconds of baseline recording were made, followed by two minutes with tape running and the maximum score, corrected for baseline readings, was recorded. Patients were told that these measures were intended to study responses to the new drug. Some patients identified the tests as 'psychological', but none objected to the procedures.

\section{STATICAL METHODS}

The chi-square test, corrected for continuity or calculated to show linear trends where appropriate, was used to assess statistical significance. The Fisher
Exact Probability test was used when small numbers made the use of the chi-square test inappropriate.

\section{Results}

Fifty-eight patients completed the trial successfully, of whom 29 received the anti-peptic drug and 29 received placebo tablets. The patients comprised 46 men and 12 women, with a mean age of 42.5 years $(\mathrm{SD} \pm 14.9)$. The social class distribution of the trial subjects is shown in Table 1, with Dundee and Lewisham census figures for comparison.

Table 1 Social class distribution

\begin{tabular}{lrlllll}
\hline & \multicolumn{7}{l}{ Social class $(\%)$} & & \\
\cline { 2 - 6 } & $I$ & $I I$ & $I I I$ & $I V$ & $V$ \\
\hline Dundee 1971 census & 4 & 12 & 50 & 22 & 12 \\
This study-Dundee & 11 & 14 & 36 & 28 & 11 \\
This study-combined & 6 & 14 & 44 & 20 & 16 \\
This study-Lewisham & 0 & 15 & 52 & 18 & 15 \\
Lewisham 1971 census & 13 & 40 & 25 & 15 & 7 \\
\hline
\end{tabular}

Three Dundee cases omitted-social class not recorded.

The reasons for the differences in social class structure between the census populations and the samples studied in each area are unknown. These biases did not appear to affect the results recorded below.

The outcome in terms of healing and symptom relief is shown in Table 2.

Table 2 Outcome

\begin{tabular}{|c|c|c|c|c|}
\hline & \multicolumn{2}{|c|}{ Healed (no.) } & \multicolumn{2}{|c|}{ Not healed (no.) } \\
\hline & $\begin{array}{l}\text { Symptom } \\
\text { relief }\end{array}$ & $\begin{array}{l}\text { No symptom } \\
\text { relief }\end{array}$ & $\begin{array}{l}\text { Symptom } \\
\text { relief }\end{array}$ & $\begin{array}{l}\text { No symptom } \\
\text { relief }\end{array}$ \\
\hline \multicolumn{5}{|l|}{ Dundee } \\
\hline Active drug & 10 & 4 & 0 & 2 \\
\hline Placebo & 7 & 4 & 0 & 4 \\
\hline \multicolumn{5}{|l|}{ Lewisham } \\
\hline Active drug & 5 & 1 & 4 & 3 \\
\hline Placebo & 6 & 0 & 3 & 5 \\
\hline Total & 28 & 9 & 7 & 14 \\
\hline
\end{tabular}

There was no significant difference between the active drug and placebo as regards healing or symptom relief. Healing occurred in 37 patients of whom 17 were receiving placebo, a response to placebo of $55 \%$.

Healing rates differed in the two centres, as 12 of 22 ulcers healed in Lewisham (six healed of 14 receiving placebo), compared with 25 of 31 in Dundee (11 healed of 15 receiving placebo), $(\mathrm{P}<0 \cdot 01$; chi-square test, corrected for continuity; two-tailed). Relief of symptoms was reported by 18 of 27 
patients in Lewisham (nine of 14 receiving placebo), and 17 of the 31 in Dundee (seven of 15 receiving placebo); this difference was not significant.

Because there was no significant difference in outcome between placebo and active drug, the data from all the patients were pooled for the remaining analyses. Twenty-eight of the 37 patients whose ulcers had healed reported symptom relief, while seven of the 21 whose ulcers had not healed reported symptom relief. The association between healing and relief of symptoms is significant $(P<0.01$; chisquare test corrected for continuity; two-tailed). None of the other variables examined in the study showed any significant association with healing. Regardless of treatment, symptomatic relief was associated significantly with the sex of the treated patient, being more frequent in male patients than female. There was also a correlation with social class, with significantly more frequent symptomatic relief in higher social classes. The correlation between social class and healing did not reach a significant level. Symptomatic relief was also significantly more frequent in patients with low GHQ scores (Table 3).

Eighteen of the 25 patients who expected to be cured reported symptomatic relief, while none of the three patients who did not expect any benefit from treatment had relief of symptoms $(P=0.036$, Fisher Exact Probability test, one- or two-tailed). The remaining 26 patients (four having failed to answer) who had been uncertain about the outcome of their treatment or who had not expected outright cure showed no significant association between expectation and outcome.

Scores on the Body Sway test were not significantly associated with any other variables and showed no difference between those who responded to the placebo with healing or relief of symptoms and those who did not.

\section{Discussion}

The ulcers of 17 patients healed during treatment with placebo, and a group of 16 patients reported symptomatic relief after treatment with placebo. In this study the outcome for the patients treated with the active drug was not significantly better than for those treated with placebo. The following variables also failed to predict healing of ulcers: age; sex; social class; duration of illness; previous experience of treatment; expectations of cure or symptom relief; presence of psychiatric problems; and suggestibility.

The reason for the difference in healing rates between the patients in Dundee and Lewisham whether on the active drug or not is not clear from our results. It may be attributed to differential
Table 3 Factors associated with symptom relief

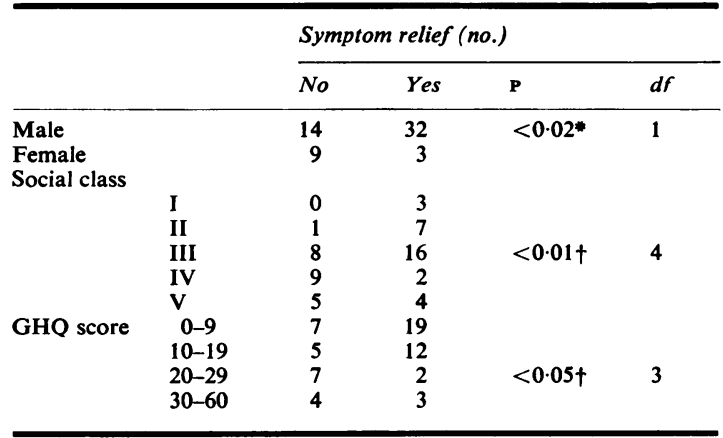

*Chi-square test, corrected for continuity, two-tailed.

†Chi-square test. Linear trend also significant, $P<0.01$.

expectations on the part of the physicians involved in the two centres. ${ }^{7}$ Also, the natural history of peptic ulcer may differ from one region to another.

The greater incidence of symptomatic relief in males and in patients in the upper social classes differs from the results of previous studies on placebo responses. ${ }^{8}$ It seems possible that men are less willing to see themselves as 'ill' and more willing to believe in the efficacy of treatment. It is known that middle-class patients benefit more from the health services and may therefore tend to have more confidence in their treatment. ${ }^{9}$

The tendency for 'expectation of cure' to be related to a satisfactory level of symptom relief confirms other studies ${ }^{10}$ but we found no association between symptomatic relief and previous experience of treatment for duodenal ulceration, unlike Batterman and Lower. ${ }^{11}$ Similarly, we did not confirm reports ${ }^{12}$ that the duration of the illness and the previous treatment received affected placebo response. The association of low GHQ scores and symptomatic relief confirms previous findings that the placebo effect is not associated with psychiatric disturbance ${ }^{10}$ and in this study it was positively associated with the absence of psychiatric disturbance. Such absence might favour a more benign course in any case.

The failure of the Body Sway test to predict response to placebo was unexpected. Suggestibility as measured by this test has been closely linked with the placebo effect by several workers. ${ }^{510}$ Our results do not confirm a relationship between these two phenomena, thus confirming Evans'13 findings.

We conclude that a positive placebo response relates to a positive expectation of complete cure and is not dependent on suggestibility. In this study male patients, those of higher social class, and those with low GHQ scores had the best outcome in terms of symptom relief, but the illness may have a more benign natural history in this group. 
Thanks are due to Mr S Ogston for statistical advice. K G Wormsley gratefully acknowledges a research grant from the Scottish Hospital Endowments Research Trust. Copies of the original data are available from the authors on request.

\section{References}

${ }^{1}$ Halter F. Spontanverlauf des peptischen ulkus (Natural causes of peptic ulcer disease). Schweiz Rundschau Med (Praxis) 1978; 67: 1870-6.

${ }^{2}$ Evans FJ. The placebo response in pain reduction. In: Advances in Neurology vol 1; New York: Raven Press, 1974: 289-96.

${ }^{3}$ Trouton DS. Placeboes and their psychological effects. $J$ Ment Sci 1957; 103: 344-54.

${ }^{4}$ Goldberg DP. In: The detection of psychiatric illness by questionnaire. London: Oxford University Press, 1972. ${ }^{5}$ Eysenck HJ. In: Dimensions of personality. London: Routledge and Kegan Paul, 1947.
${ }^{6}$ Eysenck HJ. In: The scientific study of personality. London: Routledge and Kegan Paul, 1952.

'Sarles H, Camatte R, Sahel J. A study of the variations in the response regarding duodenal ulcers when treated with placebo by different investigators. Digestion 1977; 16: 289-92.

${ }^{8}$ Beecher HK. The powerful placebo. JAMA 1955; 159: $1602-5$.

${ }^{9}$ Cartwright A In: Social class variations in health care and in the nature of general practice consultations. London: Institute for Social Studies in Health Care (mimeo), 1975.

${ }^{10}$ Tibbetts RW, Hawkings JR. The placebo response. $J$ Ment Sci 1956; 102: 60-6.

"Batterman RC, Lower WR. Placebo responsivenessthe influence of previous therapy Curr Ther Res 1968; 10: $136-43$.

${ }^{12}$ Rickels K, Lipman R, Raab E. Previous medication, duration of illness and placebo response. J Nerv Ment Dis 1966; 142: 548-54.

${ }^{13}$ Evans FJ. Suggestibility in the normal waking state. Psychol Bull 1967; 67: 114-29. 